Historic, Archive Document

Do not assume content reflects current scientific knowledge, policies, or practices. 

$L I$ is $F A R$ REICEN VID

1909 CataloG

U.S. Department of $A$

SIRAWBERRY PLANIS

क5:

5 का

उत्?

(5)

ป

M. CRAWFORD COMPANY CUYAHOGA FALLS, OHIO 


\section{A Few Words to Our Friends.}

We thank you sincerely for past favors, and extend our best wishes for your prosperity and happiness in the year just opening.

The spring of 1908 was a very favorable one for shipping plants. We begun work about the middle of March, some two weeks earlier than usual, and continued throughout the season with no serious interruptions. Our one drawback was a shortage of plants, and this seems to be the general complaint. We sold nearly everything and returned many orders. The coming season bids fair to be a repetition of last in this respect, owing to the very dry weather through the autumn months.

We offer several new varieties which amateurs and others will be interested in testing, and our list of standard sorts comprises a large number of the best, though in some instances we have only hundreds where we expected there would be thousands.

You who have dealt with us before know that the plants we ship are fresh from the field, trimmed with care, tied in bunches of twenty-five each, and packed with plenty of moss. For express orders we use light crates-for small ones baskets, thus making the charges as low as possible. It may not be known to all plant buyers that express companies make a special rate on this class of goods, deducting twenty per cent. from merchandise charges, and transporting small quantities at hundred-pound rates. The minimum charge, however, is thirty-five cents. We have the Adams and U. S. companies.

Our plants are true to name, and warranted to give satisfaction. If by delay or accident in transit they are injured or destroyed we make good the loss, provided that such loss is reported promptly. If mistakes occur, which seldom happens, we rectify them with pleasure. In case of loss from any cause, it is mutually agreed that we shall not be liable for an amount greater than that paid us for the stock.

Our business is largely retail, and small orders receive the same careful attention that is accorded to larger ones. Every package of plants is accompanied by a certificate of inspection.

It is our custom to acknowledge receipt of orders promptly, and if you do not hear from us within a reasonable time, it would be well to write again. With express orders we send cards of notification by mail.

Our terms are cash before shipment, except in dealing with experiment stations and other public institutions.

Remittances may be made by money order-post office or express-bank paper, or registered letter. Small sums may be sent in stamps.

We cannot urge too strongly the advisability of ordering early. Many of our customers have adopted the wise plan of sending in their orders as soon as they can make their selections from our catalog, and remitting when they notify us to ship. By following this course you will make sure of getting what you want, which will be a doubtful matter with late orders this year.

In case we should be out of any variety ordered, please state whether we shall return the money or send some other kind equally as good, or better. When ordering late in the season it is an excellent plan to name a second choice, as it often saves valuable time. Beginners sometimes state their wants and leave the selection of varieties to us.

It is our wish to send out every order at the time that will best suit the buyer, and it will be a great help to us along this line if you will state your preference as to date of shipment. If you cannot do this in advance, it will answer our purpose as well if you direct us to ship when notified, and then write at the proper time.

It is our aim to serve our patrons well, to furnish good plants, true to name, and deliver in first class condition, but we do not assume to be superior to all others in the business in these respects. 


\section{Strawberry Culture in Brief.}

For the benefit of those who are anxious to learn the rudiments of the business, we give a condensed outline of directions.

Any soil that is good for corn or potatoes will grow strawberries. The best is that which contains an abundance of plant food, and plenty of moisture, with good drainage. It is not advisable, however, to plant them after corn, as the corn-root aphis, which has become somewhat prevalent of late, is liable to affect the roots of the strawberry plants, also.

The ground should be well plowed and thoroughly harrowed. It may be enriched with barnyard manure or commercial fertilizer. The former, if old and well decomposed, should be applied after plowing and before harrowing, so that it may be worked into the soil, and still remain near the surface. If fresh manure is used it should be spread over the ground in the winter and allowed to leach, and if it contains much litter this should be raked off before plowing. When commercial fertilizer is used it may be scattered around the plants two or three weeks after setting, at the rate of about five hundred pounds to the acre, or a moderate handful to each plant. It must not touch the foliage.

Spring is the best time to plant strawberries, and the earlier the better. Before growth commences the plants are ripe and tough, and it does them very little harm to be transplanted, but after they have put out young, tender leaves and roots the change affects them more seriously, especially if the weather comes hot and dry soon after.

When ready to set the plants, if they have not already been trimmed, take off all the old leaves and runners, and shorten the roots to three inches. Place them in a pail containing about two inches of water, and take them out one by one, as wanted. Set them as deep as they grew before, taking special care not to cover the crowns. The roots should be spread out in fan shape, and the earth pressed firmly about them. In due time blossoms will appear, and these should be promptly cut off.

It sometimes happens that plants ordered from a distance arrive at a time when they cannot be set at once. In such a case they should be heeled in, that is, set close together in a temporary bed. The rows may be four or five inches apart, and the plants an inch or two in the row. When set in this way they can be shaded and watered if necessary. They may be allowed to remain in this temporary bed for several weeks, until they have made a good growth of new, white roots, and then taken up with as much soil adhering as possible and planted out permanently.

From the time the plants are set until fall the ground should be stirred often, to conserve the moisture and destroy the weeds. If deep cultivation is practiced it should cease early in the fall, as at that time the plants send out new roots near the surface, which should not be disturbed. The weeds that appear after cultivation is discontinued will be killed by frost a little later on.

In the northern states strawberries need some protection in the winter, by a light covering, say two or three inches, of straw, leaves, or any litter that will shade the ground and hold the snow. This should be put on late in the fall, and removed from over the plants about the time they start into growth in the spring. It may be left between them and in the paths, as a mulch. The main want of the strawberry at fruiting time is water, and this is an excellent mode of keeping the ground moist. It also keeps the fruit clean.

There are three popular methods of growing strawberries, according to the wishes and purposes of the growers, - the matted row, the hedge row and hill culture. By the first the runners are allowed to grow without restriction; by the second each plant is permitted to set a limited number of new ones, and beyond these the run- 
ners are kept cut; by the third the runners are cut from the beginning, and never allowed to grow more than a few inches in length. The first costs the least work, and as a rule yields the most quarts of berries to a given space, but they are not the largest. The second involves more labor and produces larger fruit, but not quite as much to the acre. The third requires the most attention and gives the finest berries in return. When plants are to be grown in matted rows or hedge rows, it is a good plan to cut off the first runners. Those that are sent out later will be larger and make better plants.

For farmers who have neither time nor inclination to do what seems to them like "puttering," there is an easy way to have an abundant supply of strawberries for family use. This can be done by leaving a few square rods in some corn or potato field, and setting this space to strawberry plants in rows ccntinuous with those of the farm crop. In this way all will be cultivated and hoed together, and the strawberry corner is likely to prove the most satisfactory portion of the field,-perhaps the most profitable as well. True, there will be a break in the field the next year which will be somewhat inconvenient, but it will pay to work around it.

There is a great difference in the size of plants, some varieties naturally making very large ones, others medium, and still others small. The largest plants of Senator Dunlap and Warfield are hardly equal to the culls of Marsliall or Uncle Jim, and yet the smaller ones endure hardship fully as well as the larger, even better, and are far more prolific in making runners. It is well for buyers to be aware of these facts, to guard against disappointment when they receive plants that are constitutionally small.

Distances in planting vary according to the method of cultivation adopted, and the nature of the varieties used. As a general rule the rows may be three and one-half feet apart. For the matted row, ordinary kinds may be set two feet apart, or a little more, in the row, and fast runners like Senator Dunlap, four. If the plants are to be grown in hedge rows or by lill culture, a foot and a half is about right.

The number of plants required for an acre, set at any given distances, may be easily computed. One acre contains 43560 square feet, and this number divided by the number of square feet occupied by one plant will give the number of plants to the acre. For instance: If the plants are to be set three and one-half by two feet, multiply these numbers together and the product is seven, the number of square feet required for each plant. Seven is contained in forty-three six times with a small remainder, hence, a few more than 6000 plants will be needed. Again: Suppose the plan is three and one-half by one and one-half; multiply seven halves by three halves and the result is five and one-fourth, which is contained in forty-three about eight times. Therefore the required number of plants is 8000 .

\section{Perfect and Imperfect Blossoms.}

Strawberry blossoms are popularly designated as perfect and imperfect, or staminate aud pistillate.

Perfect or staminate varieties combine both sexes, and are also called bi-sexual. They have both stamens and pistils, axd are able to fertilize not only their own blooms but also those of pistillate sorts.

Imperfect or pistillate varieties have pistils but not stamens. They produce no pollen, and therefore their blossoms nust be fertilized from other sources. In planting imperfect varieties every fourth or fifth row should be set with some perfect sort.

For use in our catalog we have chosen the terms "perfect" and "imperfect," marked P. and I. 


\section{Selection of Varieties.}

What to plant is an important matter with the strawberry grower. He has many things to consider, and the safest way to decide what kinds are best suited to his locality, his land, and his market, is to study the descriptions of the different varieties, and test those that seem most likely to answer his purpose. In this little book we give the results of our observations, which we hope may be helpful, but our conclusions, however carefully drawn, can not take the place of actual test with others.

\section{Our Introductions.}

Of the strawberries described in this catalog, the following were brought out by M. Crawford or M. Crawford Company: Brandywine, Empress, Gill, Helen Gould, Highland, Kittie Rice, Margaret, Matthew Crawford, Miller, Mrs. Miller, Nick Ohmer, Sen. Dunlap, Victor, Wm. Belt and Woolverton, fifteen in all. Four of these, Helen Gould, Kittie Rice, Matthew Crawford and Mrs. Miller, were given to customers as premiums on orders.

\section{Strawberries for Canning.}

We have found by careful experiments that there are very many varieties which are good for canning, and very few which are not. Nearly all kinds will be red and handsome in the cans if plenty of sugar is used. We may say that Commonwealth, Ekey, Helen Gould, Highland, Kittie Rice, Mrs. Miller, Uncle Jim and Wonder are especially fine for this purpose, but there are many others that are excellent.

\section{Classes.}

For convenience we give alphabetical lists of the early, medium and late varieties.

EARLY.-Arnout, Aug. Luther, Climax, Early Ozark, Fairfield, Fendall, Gill, Glen Mary, Goldsborough, Goree, Haverland, Jim Dumas, Marshall, Norwood, Pride of Mich., Red Bird, Goldsborough's St. Louis, Sen. Dunlap, Taft, Warfield.

MEDIUM.-Abington, Blaine, Bountiful, Bubach, Cardinal, Colossus, Cooper, Dicky, Ekey, Golden Gate, Gray's Dollar, Great Scott, Helen Gould, Highland, Kittie Rice, Margaret, Matthew Crawford, Miller, Mrs. Miller, Nick Ohmer, North Shore, Outlander, Parsons' Beauty, Pocomoke, Saratoga, Wm. Belt, Woolverton, Wooster.

LATE.-Autumn, Battenburg, Brandywine, Commonwealth, Empress, Evening Star, Fremont Williams, Gandy, July, Latest, Nettie, Orem, Oswego, President, Sample, Stevens, Uncle Jim, Wonder.

\section{Descriptions.}

\section{Recent Introductions Which We Now Offer For The First Time.}

A few of the varieties named under this head were brought out two years ago, and two or three earlier than that, but the most of them were new last year. The list is longer than usual, and we hope that among so many that have shown superior merit at home there will be some that will do equally well abroad, and prove to be generally useful.

AUTUMN. I.-Late. From Samuel Cooper of Delavan, N. Y. The plant is of medium size and a good grower. Fruit roundish conical, color glossy red, flesh firm and very red, flavor rich and sprightly. It has a fine aroma, and is altogether a very desirable acquisition, Mr. Cooper recommends it as a fall bearing variety, 
but as it is pistillate it needs some perfect sort that blooms at the same time to fertilize it. If a fall crop is desired the spring fruit buds should be removed.

BATTENBURG. P. - Late. This was originated by that very successful amateur grower, Arthur T. Goldsborough, of Washington, D. C., wlio has produced several fine varieties and the largest berries ever grown in this country or any other. From his description of Battenburg we compile the following:

"This sort is not very tall, but is stocky, with ample foliage for bloom and fruit protection. It is healthy and vigorous, crowning up well, and sending up fruit stalks as the season advances. This habit prolongs the fruiting season, and makes the berry later than Gandy. It blooms late. The runners are strong, and without internodes. The king berry is not the main berry on the first truss, but is carried on an independent fruit stalk. Each plant turns out one of these fruit stalks. The main berries on the cluster are of great size, and there are very many of them. Like all great croppers, the fruit lacks sugar and flavor. Its color is not attractive, and the earlier berries are bad in shape. The later pickings are of better sliape, color, quality and flavor. With so many undesirable points, it might be asked, why introduce it? In the first place, many growers like quantity rather than quality, and buyers are not as discriminating as they n11ight be; besides, the Battenburg has several points to commend it, unusual size, productiveness, and late bearing. It has produced many berries runıing fron two to four ounces on a single sten."

Mr. Goldsborough requests dealers who sell his berries to give the bad as well as good points of each sort. He also requests that his name be prefixed to the name of the berry, so this is Goldsborough's Battenburg.

BLAINE. P.-Midseason. A cross between Beder Wood and Lovett; originated by J. W. Blaine of Iowa. It is recommended as producing "large, stocky plants with very healthy foliage and broad leaves; plenty of runners for a good crop; and large, firm berries of good color, and the best flavor." Mr. Blaine adds, "The best shipper I liave ever raised, and I have tested over a hundred varieties."

BOUNTIFUL. P.-Early medium. This is a seedling of Glen Mary, originated on the Kenridge Fruit Farm in New Jersey, nine years ago. Plants were sent to experiment stations in different parts of the country, and from their reports the following general description has been deduced: "Plants large, vigorous, and numerous, with dark green foliage. A good yielder, holding its size well. Fruit large, showy, and attractive; roundish conical, sometimes slightly flattened. Flesh red, juicy, moderately firm, and of good flavor. Calyx medium to rather small."

COLOSSUS. I.-Midseason. This is not very new, but we have not had it before. It is a seedling of Bubach, and much resembles that famous variety in both plant and fruit. Berries large to very large, as its name implies. Very productive. A money maker.

GRAY'S DOLLAR. P.-Mediun1. A native of Indiana. We quote from Mr. Gray's description: “A rank grower and good plant maker; succeeds everywhere. The roots run deep and withstand both drought and freezing. Berries large, perfectly formed, pointed and glossy, bright rich red color, and the finest flavored, as well as the solidest, best shipper ever introduced. Each plant has from three to six fruit stems that stand up well for such an enormous load. It is the best pollenizer we have ever grown. Its foliage is light green and never shows any rust or spots. It possesses the good qualities of all our old varieties without their faults."

EARLY OZARK. P.-Early. This berry was introduced a year ago by Charles Shull of Missouri, after he had fruited it five years. He describes it as "the largest extremely early berry ever introduced." It is a cross between Aroma and Excelsior, and has large blossoms which are rich in pollen. Foliage dark green, large and 
healthy. Plant very productive. Fruit firm, good, and very large. Mr. Shull says: "Fifteen berries filled a quart rounding full, the berries measuring five and one-half inches around." He also states that it is very hardy in resisting frost.

EVENING STAR. P.-Late. From Missouri. A seedling of Gandy, grown by James Sons, Jr., in 1902. He states that it is larger in fruit and plant than Gandy, and twice as productive. It ripens at the same time. The plant makes a great mass of fibrous roots, and the fruit stems are as large as a lead pencil. The berry is bright red, perfect in shape, and has a large, double, green calyx.

FREMONT WILLIAMS. P.-Late. Originated in Arkansas by Hubach and Hathaway, who pronounce it "the best late strawberry; as fine in shape and color as Gandy, as large, and holds its size to the end of the season; ripens with Gandy, but holds out longer; a good yielder, a fine shipper, and of excellent flavor. Plants large, strong, and deep rooted, with large foliage, It is also a good plant maker."

The Ohio Experiment station in its 1906 report says: "Fremont Williams again surpassed Gandy on our soil as a late, large, fancy berry, It is so firm that it keeps for a remarkable length of time after picking. It is superior in size and beauty to the Gandy, and produces more fruit upon a given area."

GOREE. P. - Early. A native of Texas, beginning life as an accidental seedling in 1902. It was introduced in the fall of 1907 and spring of 1908 , by T. V. Munson \& Son. We make quotations from their catalog: "The vine is a strong, handsome grower and a good plant maker, enduring with impunity the hottest and driest weather, in both the black waxy soil of Mr. Goree's place, and the thin sandy soil of Denison. The foliage is of a dark, glossy green, and perfectly healthy. The flowers are perfect and profuse, setting an enormous crop of berries which ripen out perfectly and are very firm, the best of shippers. The berries are from medium to large, heart-shaped, regular and uniform to an unusual degree, ripening all over, of a very rich, glossy, crimson scarlet, and shire as if varnished; seeds golden, prominent.

"Its quality is its crowning glory. It is exceedingly aromatic, and has in the highest degree the richest, sweetest, true wild strawberry flavor. Flesh solid crimson." The Goree has borne a second crop in Texas every year but one since the beginning of its cultivation.

JIM DUMAS. P.-Early. This was originated by that very successful propagator, Louis Hubach of Arkansas, who produced Fremont Williams and other valuable varieties. He states that the Dumas combines the blood of Barton's Eclipse, Gandy and Excelsior. He describes it as having "strong, healthy foliage, and very stiff, long roots; a good plant maker and has never shown any sign of rust or blight. The berries are very large and perfect,running from 16 to 24 in the box the first week or two, and then dropping to 30 or 40 . The berries ripen nearly as early as Excelsior, and average twice as largc. Unlike most large kinds it is a great yielder, and holds out during a long season. The flesh is red all through, and of good flavor." Mr. Hubach farther says that he has tried it on clay, gravel, sand, and low ground, and it has done well under all conditions. He considers it the best early strawberry ever introduced.

NORWOOD. P.-Medium early. Found on the grounds of Mr. N. B. White of Norwood, Mass. It is supposed to be a cross between Marshall and Corsican. IVe quote Mr. White's description: "The plant is strong and healthy, making a liberal but not excessive number of strong runners. The berry is conic and regular in shape; not a cockscombed berry was found this season. The quality is unsurpassed, and the size unequaled, some attaining the enormous size of three inches in dianeter. Four such strawberries would fill a box and be crowded. Color bright red all 
the way through, growing darker with age; firm, a good keeper, and will ship well. Holds its size well through the season, and remains in bearing a long time."

Last year the entire stock of Norwood plants was purchased by L. J. Farmer, and the retail selling price was ten dollars a dozen.

OREM. P.-Late. A native of Maryland, introduced last year by J. H. Arndt. We make free quotation from his circular:

"I have raised dozens of varieties of strawberries, but have never had any other to equal the Orem. It has always been a sure cropper, regardless of season. It has been tried on all kinds of soils, and does well on any, but particularly well on heavy soil. It is a vigorous grower, and has fine foliage to protect the beautiful berries from the hot sun. It comes in with the Gandy, and bears an abundance of flne berries even two weeks after the Gandys are all gone. It bears about three times as many as the Gandy. The berries are exceedingly large and smooth, light red with light yellow seeds and dark green calyx which makes them very attractive, and they ripen all over. They hold their size best of any I ever saw, and are good keepers. They can be left on the vines two days after they are ripe, and still be in first class condition for market. The flavor is excellent. This is, without exception, the most wonderful strawberry ever introduced."

OUTLANDER. P.-Midseason. Another of the productions of Mr. A. T. Goldsborough, and called "Goldsborough's Outlander." From his catalog we copy the following:

"Name suggested by its long runners and far-flung fruit stalks. In the Haverland class as to type-omitting its defects and improving its good points. The Outlander is unique, and one of its distinctive traits is its habit of developing the king berry $\mathrm{MUCH}$ in advance of the rest on the truss. After it is picked the rest are better sap-fed, and reach a fine uniform size and are exceedingly attractive in shape and color. They are oval with a neck and a handsome green calyx which flares back, making capping easy. They show up well in the crates, and should prove good shippers. Some of the king or first berries weigh over one and one-half ounces. It colors up evenly, a bright red, with darker hue where sun strikes. Flesh pinkish. While not an acid berry its flavor is only fair. Every blossom makes good."

Outlander won the gold medal awarded for the largest strawberries at the Jamestown Exposition.

PRIDE OF MICHIGAN. P.-Medium early. The name of the berry reveals the place of its origin, and it was introduced from the same state in 1906, by O. A. E. Baldwin. His description is so comprehensive and well condensed that we use it with some slight omissions:

"Plant very vigorous and healthy, a good plant maker. Fruit stems strong, stand up well, and there are plenty of them. Productive-will out-yield any other variety. Size and shape about like Haverland, rather oblong. Color dark, glossy red. Shipping quality the best; very tough skin and firm berry. Plant is perfect and berry is perfect."

ST. LOUIS. P.-Early. Distinguished as Goldsborough's St. Louis. Of this great berry the originator says:

"This is the result of a cross between Laxton's Commander and Goldsborough's Heart Flusb, a seedling whose parents were the British Queen and the French berry, Louis Gauthier. It therefore has no American blood. Its fruit resembles the Commander. The plant is not as large. Leaves a third smaller and darker green. It is a free runner maker, with good cat's teeth roots which strike quickly. Plant free from leaf or other disease. The St. Louis has a fine sun burst of buds which 
show early. The blossoms are large. Being prolific, it requires thinning for large specimens. The king berries are irregular in shape. Those following are better shaped. Color rich, bright red. Of good quality, and flavor as good as Brandywine."

The actual size of the largest St. Louis berry was $311-16$ inches by $31 / 4$ inches in diameter. Weight $43 / 4$ ounces. This berry, with some others, was presented to the Horticultural Department at Washington, where it was officially measured and weighed, and a record made of its dimensions.

This variety captured first honors at St. Louis in 1904, and some plants were sold at that time. Since then another berry of the same name has been disseminated fronı Arkansas. The rules of the United States Pomological Society give priority to him who first publishes the name. Accordingly the name of the Arkansas berry should be changed, and probably will be.

TAFT FROM GOLDSBOROUGH. I.-Season second early and long. This is Mr. Goldsborough's favorite among the numerous fine varieties that he has originated anu placed before the public. We give his own description from his last year's catalog:

"' 'Taft' was fruited in 1906, and is, in my humble opinion, as near perfection as any sort I ever expect to see. It is a large 'Queen' without its plant weakness. There may be some small fruiting sort as sweet, juicy and well flavored, yet no large fruiting sort having these qualities so fully developed is now before the public as far as I can learn. Fruit round and regular. Color dark red. Flesh same color. Its prominent yellow seeds are well spaced. Flavor sweet and rich. Fragrant and juicy. No single stem ierry is larger, shape considered; and no sweet sort more prolific. Blooms and fruit protected by large round leaves. It makes just the right number of good, strong runners, and its foliage and roots are thus far extra healthy. It can be fruited twice or oftener, but for best fruit and private gardens I advise always single year culture and narrow rows. Largest berries are produced from summer or fall setting if lifted with plenty of soil. I never saw a big strawberry picked from a spring-set plant. If you have a taste for a sweet, true strawberry flavor, grow the 'Taft.' No sweeter than 'Goldsborough' but one=third larger. From the thousands of seedlings fruited in fifteen years or more, I select this as the nearest approach to an ideal strawberry. Do not confuse my 'Taft' with the 'W. H. Taft,' a seedling sent out this year by a Binghampton, N. Y. firm.

WOOSTER. P.-Midseason. Discovered on the farm of E. W. Wooster in Maine, in the summer of 1904. Supposed to be a seediing of Clyde and Sample. $\mathrm{Mr}$. Wooster states that it first attracted attention by its load of fine fruit. He ob= served that the foliage stems were remarkably long and upright, and that the fruit stems were also long, but weighed to the ground by their immense load of ripe and green berries, all of fine form, resembling Sample in that respect, and also in color, but in the way the seeds were set in the flesh they were more like Clyde. The quality was found to be much better than either of the parent varieties. Mr. Wooster introduced this berry last year at a moderate price, and we obtained our plants from him. Although new, and evidently valuable, it is not dear, but comes within the reach of all.

\section{Varieties Which We Have Sold Before.}

We have described these in former catalogs, and frequently quote from them in the following pages when speaking of well established kinds that present no new developments from year to year. The descriptions reproduced were written with care, and are as correct as we can make them. 
ABINGTON. P.-Midseason. This excellent variety has fruited three times with us, and we value it highly. The plant is large, lealthy, thrifty and productive. It is a good plant maker, and the runners take root easily. The foliage is dark green and covers the bloom. The blossom is large and full, making it a good pollenizer. The fruit is large and good. It has a firm surface, which enables it to bear handling well, and makes it a good shipper. In color it is a bright red which extends half way to the center, shading to white in the heart. It holds its color well after being picked, and makes a long season. It ripens with Bubach, and is likely to supersede that variety to a considerable extent, as it is firmer, brigliter in color, and better in flavor.

ARNOUT. P.-Medium early. This makes a large plant, and sends out a sufficient number of runners, which take root without trouble. The fruit stalks are large and strong, and the blossoms are well protected by the foliage. It is very productive and the fruit is of good size, broadly conical, rich red with red flesh, and excellent in flavor. It has a small green calyx and a firm skin, and the seeds are on the surface, nraking it easy to handle without becoming bruised. It ripens all over, and is easily picked. Makes a long season.

AUGUST LUTHER. P-Early. This is an old favorite, and deservedly so. The plant is small and healthy, makes long roots, and is as tough as grass. Like Sen. Dunlap and Warfiell, it shows remarkable vitality, is a great runner, and should be given ample room. The berries are of fair size, oval in form, easily picked, firm and quite good. Its earliness makes it very acceptable.

BRANDYWINE. P.-Medium late. One of the old reliables, well known and liked, especially in the south. Tlie plant is a strong grower, makes plenty of stout runners which are quick to root, and is healthy and productive. It has the fault of raising its blossoms above the leaves, which makes it susceptible to frost. The fruit is always described as heart-shaped, and very aptly so. 1t is large, firm, and high flavored, has a rich, deep color, and is protected by a large green calyx.

BUBACH. I.-Early medium. Twenty years ago M. Crawford's catalog contained the following description of Bubach, and it still holds good. Many berries have been introduced since then, a few to stay, and this is one of them. It was originated by J. G. Bubach of Princeton, Ill., in the early eighties.

"I think the commercial fruit grower will find in this a very profitable variety to raise. The plant is large, healthy, vigorous and very productive; leaves dark green and free from rust; runners, strong and abundant; blossoms, pistillate: fruit, very large; the first berries slightly irregular, but usually of good form. It ripens all over. The quality is good, though not extra. If it has any weak point it is in looking rather coarse, and this is mainly on account of its immense size."

CARDINAL. I.-Medium. This berry has always done well with us, and we have good reports of it from various localities, but in a few places it has proved a failure, which fact emphasizes our views in regard to the necessity of testing before planting largely. There is probably no variety that succeeds everywhere without exception.

The plant of the Cardinal is large, and sends out many runners, which root prompt1y. The fruit is of good size, obtusely conical, sometimes very slightly ridged, but nearly always smooth and handsome. The color is pure red throughout, the flesh is firm, and the flavor good. It has fine seeds, close together, which protect the surface. The calyx is large and gree1, and sometimes double. It makes a long season.

CLIMAX. P.-Early. A fine grower and bearer. The fruit is large and nearly round. The flesh is very red, and has a sprightly, peculiar flavor, rather tart. A popular market berry. 
COMMONWEALTH. P.-Very late. This is a thrifty grower, and makes a moderate number of runners which root as they go. It yields large crops of fine, handsome fruit, very large, and very dark red both without and within. In shape it is nearly round, slightly pointed. and the first berries are quite irregular. The seeds are bright and prominent, and the flesh is firm, sweet, and rich. Keeps a long time after being picked.

COOPER. P.-Medium to late. We fruited this last year for the second time, and anong fifty or sixty varieties it was one of the most beautiful. In shape it is conical, smooth, and perfect; in color, a fine, glossy red. Its flesh is light red shading to cream, and firm enough to make it an excellent shipper. The flavor is rich, sweet, and spirited. The fruit ripens all over, and the seeds are yellow, giving it a very bright appearance. It makes plants freely, and is a good yielder.

DICKY. P.-Medium to late. This was among our novelties last year, but we had small opportunicy to judge of its merits, for the demand for plants was so active that we sold out, and ordered more from the introducer for our own planting. From berries grown on a few old plants left standing we made the following notes: Shape, roundish; color, red; flesh, red and firm; flavor, rich and good; calyx, green and double; seeds, on surface, and skin not easily broken. The plants are very large, perfectly healthy, and wonderfully vigorous. It is said to be as productive as Sample, and to make a very long season.

EKEY. P.-Early medium, and makes a very short season. This is one of the finest berries in our collection, and we only regret that we cannot supply plants by the ten thousand, instead of in small quantities. It makes grand plants, but not very many. It yields a good crop, and the fruit is remarkably large and fine; very long, with a slight neck, dark red, and glossy. The fles 1 is also dark red and firm, and the flavor is excellent.

EMPRESS. P.-Medium to late. A Canadian berry, originated by the late John Little fifteen years ago or more, and introduced by M. Crawford in 1899. The plant is healthy and vigorous, and a great bearer. The fruit is large, conical in form, sometimes ridged but never cockscombed; dark, glossy red, firm, and of high quality.

FAIRFIELD. P.-Very early and makes a short season. This ripens a few days ahead of Sen. Dunlap, and like that famous variety is healthy and hardy, with long roots which enable it to withstand drouth. The fruit is of fair size and flavor, firm, rather long conical in shape, colors all over a rich red to the heart, and is easily picked and hulled. Although early in ripening it blooms late, thus keeping out of the way of frost.

FENDALL. P.-Early. The plants of this variety which we sold last year were obtained from the originator, Mr. Charles E. Fendall of Maryland, conseqnently we had none to bear, and must again depend upon him for our description, which we believe to be perfectly reliable. Mr. Fendall had a party of the leading men in the Horticultural Department at Washington out to see his berry last summer, and the praise they bestowed upon it endorses his own estimate of its merits. He says:

"The plant is strong and vigorous, clean and healthy. Its foliage is a beautiful light green, and as yet has not shown the slightest blemish in any respect. It throws out a great many runners which root splendidly in a very short time. The roots are large and long, often penetrating the soil to the depth of ten or twelve inches, reminding one rather of clover roots than strawberries. The berries are perfect beauties, rich in color, smooth and glossy, with long stems and very large, exceedingly showy caps. They are as large as any other variety grown, if not larger, and of delicious flavor. In length of season it is remarkable. In $1906 \mathrm{I}$ picked berries from it on the 
25th of May, and the last on the 4th of July. It yielded at the rate 16800 quarts per acre. In 1907 fine berries were picked from the Fendall from the second of June to the tenth of July."

Mr. Fendall's circular contains a picture of a single berry, actual size, as may be seen by the seeds, which measures two and fifteen-sixteenths inches across.

GANDY. P.-Late. This has been for many years the standard late variety by which all others were measured. It makes a fair-sized plant, and yields a better crop the second year than the first. It is not as productive as could be desired, but its large size, great beauty, delightful aroma and rich flavor make it profitable, and growers keep on planting it.

GILL. P.-Very early. Our attention was first attracted to this variety by the reports of the Ohio Experiment Station, where it was found to be among the earliest, and "the most productive of all the early sorts." The plant is thrifty, and nakes runners freely. The fruit is uniform in shape, nearly round, and above the average of early varieties in size. It colors all over, and becomes quite deep red when fully ripe. The flesh is light red and white, and has a pleasing flavor. It is not remarkable as a shipper, but the surface is quite firm and not easily bruised.

GLEN MARY. P.-Early. A rank grower, making strong, healthy plants with long roots. Very productive. The berries are of great size, and inclined to be rough and irregular in form, but beautiful in color, and good in quality. The Glen Mary is a good shipper, and is also popular for the home market.

GOLDEN GATE. P.-Early medium. This was introduced as early, and we have placed it in that class for two seasons, but with us it persists in ripening with the medium sorts, and we have changed it accordingly. It is a vigorous grower, and makes large plants with luxuriant foliage. The fruit is very large and beautiful, red and glossy, and the color of the surface extends half way to the center, which is white. Some of our largest specimens were wedge-shaped, but the typical form of the berry is a handsome oval. The flavor is mild and pleasant, but not rich. It ranks well for firmness. In our opinion it is an exceedingly fine variety.

GOLDSBOROUGH. P.-Medium early. From Goldsborough. After another year's fruiting, our high estimate of this beautiful berry is confirmed, and we again quote portions of the originator's description:

"The plant is tall and erect, and the berries, while not the largest, all come to perfection $i_{\mu}$ color and flavor. The shape of the fruit is perfect, color also, being a waxy light scarlet with deeper shades when fully ripe. Its red pulp leaves a red juice in a saucer, like its wild parent of the fields. It is rich, juicy, sweet and fragrant, requires no sugar, and can be freely eaten out of hand. Some of the flowers are perfect, others imperfect."

The blooms and berries are perfectly protected by the foliage.

GREAT SCOTT. I.-Medium to late. A native of Massachusetts, grown by John Scott, and named and introduced by S. H. Warren, to whom we are also indebted for Latest and Golden Gate. It makes a fine, healthy plant, with shining foliage. The berries are nearly round, sometimes ribbed, and occasionally double. They are red on the surface and light within; color all over, and are quite firm in texture.

HAVERLAND. I.-Early. Too well known to need description. We have only a few thousand plants, and one large order would take them all, hence we offer it only in small quantities.

HELEN GOULD. I.-Medium to late. This was our premium berry two years ago, and we are glad that we gave our customers something so good. Every time it fruits we admire it more and more. It does better in hills than in matted rows, and needs plenty of plant food to enable the foliage to keep up with the fruit. When 
well nourished the plant is large and healthy, and produces a great crop. It sends out a moderate number of strong runners. The fruit is large, and holds up well to the end of the season. In shape it is roundish conical, and quite uniform, though the first berry on the stem is sometimes triangular or slightly flattened, never cockscombed. In color it is a beautiful glossy red, the flesh is red, and the flavor rich and delicious, though not as sweet as that of Wm. Belt or Marshall. It is moderately firm and very fine for canning. Season medium to late.

HIGHLAND. I.-Midseason. We introduced this berry a year ago, with the co-operation of about twenty-five other dealers, on the strength of the reports sent out by the Ohio Experiment Station, where it was the most productive variety in a large collection. We gave it a fair test last summer, and found that it was fully equal to its recommendations in all respects, and superior in some. It was larger than we had reason to expect, and better in quality. We had a few quarts canned, and it proved first=class for the purpose. 'Both berries and syrup are dark red, rich and delicious. The Highland makes large healthy plants which send out a liberal number of runners. The fruit is obtusely conical, glossy red, rich and refreshing in flavor though somewhat tart, and very juicy. It is moderately firm.

JULY. I.-Very late. From H. J. Schild of Michigan. Truly a late berry. Its first ripe fruit came sixteen days after that of Gill and Fairfield. The plant is of fair size, healthy, and a good grower. The berry is a beauty. Each one is like every other, a perfect cone, brilliant red, glossy, and adorned with a fresh green calyx of medium size. The flesh is light red and very juicy. The flavor is delicious. The fruit is rather more than medium in size. It is too delicate to ship, but for home use or a near market it is fine.

KITTIE RICE. I.-Midseason. Same as Downing's Bride. This splendid berry was originated nearly twenty years ago by that prince of amateur strawberry growers, John F. Beaver of Dayton, Ohio. It has made its way steadily upwards in the list of standard varieties, until, in some localities, it is placed at the top. It is a superior berry for all purposes. The plant is a vigorous grower, healthy and productive. It makes just about the right number of runners, but they are slow in taking root. The natural constitution of the plant is such that it requires winter protection, and it is well worth the work. The fruit is large, conical, regular in form, dark red, glossy and very beautiful. The flesh is red, firm and of fine quality.

LATEST. I.-Late. This variety has been before the public five years, and has established a splendid reputation. The plant is of good size, a very thrifty grower, and a generous yielder. The fruit is conical in shape, large, long, smooth and handsome. It has the peculiarity of being dark, glossy red on the surtace and light red in the centre, with white flesh between. It is firm enough to carry well, and the flavor is rich and sweet. It seems to have but one fault,-it is inclined to lose its gloss soon after being picked, but even this does not prevent its being popular, espe. cially for a near market.

MARGARET. P.-Midseason. Like the Kitty Rice, this was produced by Mr. John F. Beaver, and they are two that any originator might be proud of. Both respond readily to extra care, and both need winter protection. The plant of the Margaret is large and healthy, with dark green foliage, and so vigorous in growth that it will bring its great crop of fruit to perfection and continue bright and luxuriant while producing an abundance of strong runners. The fruit is conical, sometimes oval, very large, dark red with a brilliant gloss, firm, and of the finest flavor. This is especially a berry for the amateur, and with his careful culture it surprises the most sanguine.

MARSHALL. P.-Medium early. One of the finest berries in cultivation. It makes a very large, stocky plant which produces a fair crop of berries of great size 
and exceeding beauty, nearly round in shape, very dark red and glossy, and firm enough to bear shipping well. Its flavor is delicious, and we place it next to $\mathrm{Wm}$. Belt for sweetness. It is tender to frost, but with good care it is both pleasing and profitable.

MATTHEW CRAWFORD. P.-Midseason. Two years ago we bought this fine berry from the originator, J. R. Peck of Missouri, and last year we gave it out as a premium. 1t is worthy of all the praise it has received. It makes a large, stocky plant with dark green, healthy foliage, and is exceedingly prolific. The berries are conical, and very uniform in shape and size. The color is a brilliant red, growing darker when the fruit becomes very ripe. It colors all over at once. The flavor is fine, and it is very firm for so large a berry.

MILLER. P.-Early medium. Originated by D. J. Miller of Holmes County, Ohio, who also produced the Mrs. Miller and the Victor, and later the King Edward, which has not yet been introduced. The Miller is a good standard sort, making large plants, which produce many runners and generous crops of fruit. The berries are very large, roundish conical and very uniform in shape, bright red in color with lighter flesh, moderately firm, and superior in quality.

MRS. MILLER. I.-Medium to late. This great berry has been growing in popularity ever since its introduction four years ago. It makes a fine, healthy plant, which brings its whole crop to maturity. The foliage is dark green and ample, protecting the blossoms and berries well. The fruit stalks are large and strong. The fruit is large to very large, oblong in form and very firm in texture. Splendid color throughout. Rich flavor, 'iut not as sweet as Wm. Belt or Marshall. Slightly rough on the surface, but not ridged.

NETTIE. I.-Very late. This variety has been in cultivation a long time, and although its color and appearance are unattractive and its quality is poor, it holds its place by reason of its extreme lateness, large size, and great productiveness, which make it profitable notwithstanding its fai!ings.

NICK OHMER. P.-Midseason. Originated by John F. Beaver, and introduced by M. Crawford eleven years ago. This is essentially a berry for the amateur. It is immensely large, of fine form and good flavor, and well repays the care which is required to bring it to perfection. It does best when grown in hills, and needs high culture and winter protection. The plant is large.

NORTH SHORE. P.-Midseason. This variety is steadily gaining in favor. The plant is of good size, a vigorous grower and a prolific yielder. The fruit is very large, and rich red thronghout, core and all. Fine close seeds, red and yellow. Heart pithy, sometimes hollow. Excellent to handle. Flavor fine. Fragrance exquisite.

OSWEGO. P.-Late. A New-Yorker, introduced two years ago by L. J. Farmer, It is of the style of Corsican, Uncle Jim, Wonder, and a few others, and there is no discount on any of them. Oswego is supposed to be a cross between Bubach and Sharpless. The plants are large and vigorous, and produce a sufficient number of runners. The blooms are generous, and well supplied with pollen. The berries are immensely large, roundish conical, moderately firm, bright red, and ripen all over. The flesh is light red, and the flavor rich and sweet.

PARSONS' BEAUTY. P. POCOMOKE. P.-Both midseason. Very similar. The two are not the same, but the differences are so slight that they may be described as one. Both are vigorous growers and very productive. The fruit is large and handsome, conical, bright red, and firm; rather tart, but popular with both growers and buyers.

PRESIDENT. I.-Medium late. This is a healthy, vigorous grower, produces a moderate number of berries, and brings them all to maturity. The fruit is of the 
very largest size, even to the end of the season, and on this account it is a great attraction. It is uniformly round when well pollenized, dark red, glossy, and exceedingly beautiful. It is remarkably firm, and the flavor is good, though tart. Like Gandy it bears well the second year.

RED BIRD. P.-Early. From Mississippi, a cross between Murray and Hoffman, both extra early. The plant is vigorous and the fruit large, roundish, red, and juicy. Flesh very red, quite firm, and pleasing in flavor, though not very sweet. It is recommended as very early in the south, but here, last season, it ripened with Sen. Dunlap, a few days after the earliest.

SAMPLE. I.-Late. For many years this has been one of our most popular varieties. The plant is large and healthy, and has wonderful roots, which enable it to resist both drouth and frost. It is a good runner, and every plant made bears fruit. The berries are roundish conical, and of good flavor. They are fine red all through, moderately firm, and large to the close of the season.

SARATOGA. P.-Medium to late. Originated and introduced by Wm. Palmer of Saratoga County, N. Y. It is a cross between Glen Mary and Sampie, and resembles both of those well-known varieties in vigor of growth. The berries are roundish, glossy red with red flesh, firm and solid. It is not as sweet as some, but the flavor is rich, and has the strawberry quality.

SEN. DUNLAP. P.-Medium early, and continues in bearing a long time. This belongs to that class of berries which make plants of only medium size but tough and hardy with long roots and a surprising capacity for enduring hardship. Such varieties make many runners and should be given plenty of room, as crowding the plants makes the fruit small. The Sen. Dunlap is very productive, and the fruit is of good size. It is conical in shape, and very uniform and handsome. The color is a deep, rich red, without and within, and the flavor is delicious. It is a first-class shipper, and retains its brightness long after being picked. It does well everywhere, and is planted more extensively than any other variety at the present time.

STEVENS' LATE CHAMPION. P.-Late. This variety makes strong, vigorous plants which yield heavy crops of fruit, and plenty of sturdy runners which take root promptly. The flowers and berries are well protected by the ample foliage. The fruit is large, long, a little flattened, and sometimes slightly creased, but generally smooth. The color is bright red, and the flesh is also red, but lighter. The flavor is good, but not the best. It ripens all over, and has a firm surface protected by prominent seeds. It is one of the best to keep after being picked.

UNCLE JIM P.-Late. Sometimes called Dornan. This makes a splendid plant with a generous green top and a great sheaf of roots that seem able to endure any amount of adversity. It is a prolific yielder and ripens its entire crop. The fruit is very large. The color is a fine red with lighter flesh, and the seeds are red. The flavor is good. Some of the first berries to ripen are slightly corrugated, but still fine looking, and those that follow are smooth and handsome.

WARFIELD. I.-Medium early. This is so well known and popular that little need be said of it. It resembles Sen. Dunlap in making small plants which mature great crops of fruit that is always in demand. The berries are conical in shape, dark, vivid red in color, and beautiful in appearance. They are firm in texture, and bear shipping admirably.

WM. BELT. P.-Midseason. We have lately seen the statement in some catalog that this is a Canadian berry, but such is not the case. and we wish to correct the the mistake. It was originated in Southern Ohio nearly twenty years ago, by the man whose name it bears, now deceased. It was introduced by M. Crawford in 1896, and has become one of the most popular varieties known, and the standard of 
excellence for flavor. The Rural New-Yorker of July eighteenth last, accords it this high honor, and adds that "it is as handsome in berry as it is good in quality." The plant is splendid for size and productiveness, and the berries are immensely large. The first one to ripen on each stem is cockscombed, but the others are uniformly conical. In years past this variety was more or less subject to rust, but it seems to have "outgrown" this tendency with us.

WONDER. P. - This grand berry has been classed as medium, while Uncle Jim, which it much reseubles was called late, but they ripen so near together that they should be placed in the same class, as late. Last season they began to ripen eleven days after Gill and Fairfield, and five days before July and Nettie. Wonder is tru!y wonderful for size of plants, luxuriance of foliage, length of roots, beauty of fruit, and productiveness. Like Uncle Jim and others of the same style it is very large, and uniform in shape, obtusely conical, except that the first berry on the stem is sometimes ribbed. Its color is a fine bright red, and light red within.

WOOLVERTON. P.-Medium to very late. An old and reliable variety. The plants are large and thrifty, and make a moderate number of short runners. It is a great yielder of large berries which are firm, and good for shipping. They are bright red, and sometimes rough on the surface, but generally conical. In some seasons they show white tips, but for the last few years they have ripened evenly with us. On account of its long blooming season this is an excellent pollenizer for imperfect varieties.

\section{Price List of Strawberry Plants}

\begin{tabular}{|c|c|c|c|c|c|c|c|c|c|c|c|}
\hline & 12 & 25 & 100 & $|250| 1$ & 1000 & & 12 & 25 & 100 & $250 \mid$ & 1000 \\
\hline Abington P.... & .20 & .30 & .75 & 1.35 & & Jim Dumas P...... & .30 & .451 & 1.00 & & \\
\hline Arnout $\mathrm{P} . . . . . . . .$. & .20 & .30 & .75 & 1.35 & 4.00 & July I................ & .20 & .30 & & 1.35 & \\
\hline Aug. Luther P.. & .20 & .30 & & & & Kittie Rice I ..... & .20 & .30 & .75 & 1.35 & \\
\hline Autumn I......... & 1.00 & & & & & Latest I............... & .20 & .30 & .75 & & \\
\hline Battenburg P... & 1.00 & 1.505 & 5.00 & & & Margaret P... & .20 & .30 & .75 & & \\
\hline Blaine P.......... & .20 & .30 & .75 & & & Marshall P....... & .20 & .30 & .75 & & \\
\hline Bountiful P ......... & 1.00 & & & & & M. Crawford P.... & .30 & .451 & 1.00 & & \\
\hline Brandywine P..... & .20 & .30 & .75 & 1.35 & & Miller P............. & .20 & .30 & .75 & & \\
\hline Bubach I... & .20 & .30 & .75 & 1.35 & 4.50 & Mrs. Miller I ... & .20 & .30 & .75 & 1.35 & 4.00 \\
\hline 1al I.. & .20 & .30 & .75 & & & Nettie I......... & .20 & .30 & & & \\
\hline Climax P... & .20 & .30 & & & & Nick Obmer P.... & .20 & & & & \\
\hline Colossus I.. & .20 & .30 & .75 & & & North Shore P.... & .20 & & & & \\
\hline Commonwealth $\mathrm{P}$ & .20 & .30 & & & & Norwood P... & 2.00 & & & & \\
\hline Cooper P... & .30 & .45 & & & & Orem P....... & .20 & .30 & & 1.35 & \\
\hline Dicky P..... & .40 & .601 & 1.50 & & & Oswego P.... & .30 & .45 & 1.00 & & \\
\hline Early Ozark P..... & 100 & & & & & Outlander P........ & 2.003 & 3.00 & & & \\
\hline Ekey P.... & .20 & .30 & .75 & $1.3 \tilde{5}$ & & Parsons' Beauty P & .20 & .30 & .75 & 1.35 & 4.00 \\
\hline Empress $\mathrm{P}$. & .20 & .30 & .75 & & & Pocomoke P....... & .20 & .30 & .75 & & \\
\hline Evening St & .50 & & & & & Pres & .20 & & & & \\
\hline Fairfield $\mathrm{P}$. & .20 & .30 & .75 & 1.35 & & Pride of Mich. P. & .20 & .30 & .75 & & \\
\hline Fendall P............. & 1.00 & 1.50 & & & & Red Bird P.......... & .20 & .30 & .75 & 1.35 & \\
\hline Frem't Will'ms P & .20 & .30 & .75 & & & St. Lo & 1.00 & & & & \\
\hline Gandy & .20 & .30 & .75 & 51.35 & & Samp & .20 & .30 & .75 & 1.35 & \\
\hline Gill P.. & .20 & .30 & .75 & 51.35 & & Sarat & .30 & .45 & 1.00 & & \\
\hline Glen Mary $\mathrm{P} . . . .$. & .20 & .30 & & 51.3 & & Sen. Dunlap P. & .20 & .30 & .75 & 1.35 & 54.00 \\
\hline Golden Gate P.... & .30 & .45 & 1.00 & & & Stevens P.... & .20 & .30 & .75 & 51.35 & \\
\hline Goldsborc & .30 & .45 & 1.00 & 1.75 & & & 2.00 & & & & \\
\hline Goree P.... & 1.00 & 1.50 & 5.00 & & & Uncle Jim P....... & .20 & .30 & .75 & 51.35 & 5.00 \\
\hline Gray's Dol & .30 & .45 & 1.00 & & & Warfield I....... & .20 & .30 & .75 & 51.35 & 54.00 \\
\hline Great Scot & .20 & .30 & .75 & 51.35 & & Wm. Belt P.... & .20 & .30 & .75 & 51.35 & 54.00 \\
\hline Haverland I & .20 & .30 & .75 & 51.35 & & Wonder P........ & .20 & .30 & .75 & 51.35 & \\
\hline Helen Goul & .30 & .45 & 1.00 & & & Woolverton P..... & .20 & .30 & .75 & 51.35 & \\
\hline Highland I. & 1.00 & 1.50 & 5.00 & & & Wooster P........... & .50 & & & & \\
\hline
\end{tabular}


The foregoing prices are by express, not prepaid.

When plants are ordered by mail, add 5 cents for each dozen; 10 cents for each 25 ; 30 cents for each 100 .

For Canadian orders the above rates of postage must be doubled.

Six plants of one variety at dozen rates; 50 plants of one variety at hundred rates; 500 plants of one variety at thousand rates.

Customers sometimes want 100 plants made up of four 25's, or 1000 made up of four 250's, and do not know what prices to affix. For this reason we have placed the price of 25 's and 250 's on our list.

Imperfect varieties (I) must have perfect varieties (P) near them.

Imperfect and pistillate mean the same; perfect, staminate and bisexual mean the same.

\section{Gladiolus Bulbs.}

We raise a large number of gladiolus bulbs, most of which are sold to seedsmen. We have on hand at this time a quantity of unculled seedlings and XX stock of choice mixed varieties.

The seedlings were grown from seed of selected varieties, much of it hand-pollenized-such as is seldom offered for sale. No two will be quite alike. There will be all colors. Out of 100 , or even a dozen, some will be very choice, and these may be marked out and the others sold or given away. It is no small satisfaction to have a few choice, selected varieties and know that there are no others in the world exactly like them.

Our $\mathrm{xx}$ stock is as fine as is offered by any firm at any price. It has been improved from year to year by the addition of choice named varieties and selected seedlings. It is much better than seedlings except that the purchaser has not the exclusive control of any variety found in it. Among the seedlings are choice varieties that may be named and kept in the family.

Blooming size, either seedlings or $\mathrm{XX}$ stock, by express, not prepaid, 25 cents per dozen, $\$ 1.00$ per 100 . By mail, 5 cents per dozen or 40 cents per 100 higher.

One-year seedlings, 50 cents per 100 by mail. These are to be grown this year, as we grow onions from sets, and will be strong, blooming bulbs in the fall.

Thousand rates on application.

\section{Blackberries.}

- The blackberry should be planted in the fall or very early in the spring. It starts into growth at the first possible chance, and the young shoots are tender, and liable to be broken off in handling. It is a profitable fruit to raise, requiring but little expense in the growing, and bringing good prices almost everywhere. The three varieties we offer are all highly recommended, and each is excellent in its way. We use last year's descriptions.

WARD. - This was discovered several years ago, growing in a fence row in New Jersey. It attracted much attention at the time, and later on, and has been steadily growing in favor ever since. It is a vigorous grower, a wonderful yielder, and perfectly hardy wherever it has been tried, so far. After an extremely cold winter in New England some years ago, it was alive to the tips. The fruit is large, handsome, and good. J. H. Hale says: "Of large size, jet black color, firm for shipment, yet tender and melting all through, without core, and of highest quality.". He also says, alluding to its productiveness: "I thought I had seen blackberries 
before, but our field of Ward caps the climax. Those rows of strong, thrifty, wellbranched plants, so literally covered with fruit that it actually clotted out nearly all the foliage, seemed almost like too much of a good thing."

The Rural New-Yorker speaks as follows in 1905: "The Ward B1ackberry,Plants set in Aprif, I904, fruited this year with considerable freedom. The canes made a short and sturdy growth, and were not in the least injured by the very severe winter. The berries are large, jet black and of best quality, with small, tender core. The market value of the berries has been demonstrated in this county by several year's experience. They carry well, not changing color after picking, and always bring top prices. We like the sturdy growth, healthy foliage and freedom from suckers. If the plants are able to resist disease, of which they have shown no trace, there is little doubt Ward will take place among our best commercial blackberries." -W. V. F.

\section{PRICES.}

Ward.--By express, not prepaid, 40 cents per dozen; $\$ 2.00$ per hundred; $\$ 15.00$ per thousand.

Six of one kind at dozen rates; fifty of one kind at hundred rates.

If wanted by mail, add ten cents for each dozen.

Root cuttings, by mail or express, 20 cents per $25 ; 50$ cents per hundred; $\$ 4.00$ per thousand.

These cuttings are of good size, and in perfect condition. They may be used instead of plants,--four by eight feet, and two inches deep.

None for sale after May first.

\section{Currants.}

The currant was a popular fruit in the days of our grandparents, and every garden had its row, generally along the fence. Then the worms came, and gradually the old rows disappeared, but after a while the virtues of hellebore were discovered, and currant growing revived. At the present time it is almost as sure a crop as it was fifty years ago, for those who are vigilent to discover the enemy, and active in applying the remedy. There has been much improvement in varieties, and with this has come a growing demand for the fruit, attended by increased profit in producing it. The two kinds that we offer are probably the best before the public.

COMET.-We obtained this from the introducer, Mr. Fell, of the Island of Jersey, in 1898 , and first offered it for sale in 1904. Some who bought plants then have ordered more since, so we conclude that they must have considered it promising. We have had it in bearing six years, and are highly pleased with it, although our fruit was grown on bushes that were trimmed close for cuttings every year. The bush is a satisfactory grower, and holds its leaves late. It is a good bearer, equal to the Victoria and other prolific sorts. It produces large bunches of large berries. Bunches have been grown containing 26 berries, almost equal to small clusters of Delaware grapes. Prof. Beach, formerly of the N. Y. Experiment Station, says that the berries will average larger than those of Perfection, which is probably the best American variety. The flavor of the Comet is excellent, and it hangs on the bushes in good condition for a long time after ripening. It has taken first prizes at exhibitions wherever shown in England.

Another year's acquaintance serves to confirm our high opinion of the Comet.

PERFECTION.-This was originated by Chas. G. Hooker, of Rochester, N. Y., who crossed Fay's Prolific with White Grape, hoping to combine the large size and color of Fay with the high quality and productiveness of White Grape. The result 
was a fine currant. It was entered for the famous Patrick Barry gold medal, and won it, the committee making the following report: "Cross between Fay's Prolific and White Grape. Season of ripening same as Cherry and Fay. Color, bright red, a good grower. Size very large, larger than Fay and Cherry. Clusters very long. Very productive, resembling the White Grape in this respect. Quality, very fine. Not so acid as Fay and other red sorts. As a table currant cannot be surpassed. A very important fact is that it has a long stem from fruit to attachment to branch, making it easy to pick."

The Perfection also received the highest award at the Buffalo Exposition, and a gold medal at the World's Fair in St. Louis.

In a recent letter from the introducers we have the following: "We have been making inquiries in regard to how the currant is doing in different sections, from the Atlantic to the Pacific, and are pleased to report that we have had nothing but words of praise from all sections. We have not received one unfavorable report."

We fruited the Perfection in a small way last summer for the first time, and were exceedingly pleased with it. For table use it is fine, for canning beautiful, and the jelly made from it is exquisitely bright in color and almost as transparent as water.

\section{PRICES.}

Comet, Perfection.-By express, not prepaid, 20 cents each; $\$ 1.50$ per dozen; $\$ 10.00$ per hundred.

Six of one kind at dozen rates; fifty of one kind at hundred rates.

If wanted by mail, add 15 cents for each dozen.

\section{A Fertilizer for the Strawberry.}

People write to me quite frequently inquiring what is the best commercial fertilizer for the strawberry. I invariably advise them to use a good "Potato Phosphate," but this is not always easily found. I have been using commercial fertilizers more than forty years, and have tried many brands, giving liberal applications, for I hate to go to the expense of producing a crop and then fail for want of plant food in the soil. In growing a crop that is as valuable as the strawberry, one cannot afford to take any great risk to save the price of a few bags of fertilizer. The difference in value between a good crop of strawberries, say two hundred bushels or more per acre, and a poor one, say one hundred bushels or less, may easily amount to several hundred dollars on a single acre. The best commercial fertilizer that I ever used is a Potato Phosphate that is worth thirty dollars per ton, and a ton is enough to enrich from two to five acres, according to the previous fertility of the land. This brand is a complete fertilizer, suited to any crop on any soil. It is honestly made, of good materials, and produces astonishing results. It is so rich that only a small amount is required. It costs no more to carry it than a brand worth half as much. It is packed in sacks containing too pounds each; price $\$ 1.50$ per sack, or $\$ 30.00$ per ton. The buyer pays the freight. Ask your agent the rate from Zanesville, Ohio. Send your order to me with the cash, and the goods will be shipped promptly.

\section{GUARANTEED ANALYSIS.}

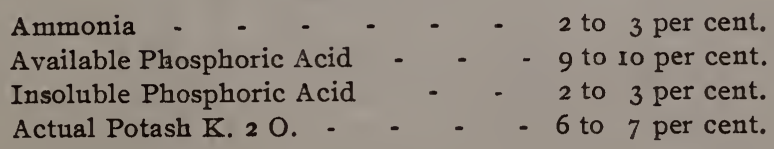

M. CRAWFORD. 
We have found by experience that some who would like to use fertilizer would also like instructions for applying it.

For strawberries, one way is to put it in with a grain drill, after the ground is prepared for planting, about a week or ten days before the plants are to be set, thus giving it time to become somewhat blended with the soil. By this method the entire surface is enriched, and for growing fruit in wide matted rows it has the advantage of giving all the plants an equal chance.

Another way, and the one we have adopted, is to wait a short time after the plants are set, until they have started into gr $\lrcorner$ wth, and then apply the fertilizer by hand, strewing a small quantity around each plant. Care must be taken not to let it touch the leaves, as it is liable to burn them. For this reason it should be put on when the air is still, and also because a wind, or even a gentle breeze carries away the fine dust, and thus a portion of the richness is lost. When applied in this way the amount used may be divided, and part put on in the spring, say two-thirds, and the ramainder in Sept ber, thus giving the runner plants a share. The amount requiralis exceedingly abiable, according to the previous fertility of the soil, and the results aimed at. From 400 to 1000 pounds per acre may be used, and even snore if desired. We grow strawberries for plants, on land that is in good condition, and it is our custom to apply about 600 pounds per acre each year.

\section{Everbearing Strawberries.}

All who receive this catalog will be interested in knowing that we have at last found a true ever-bearing strawberry. We have had the Pan-American for a few years, and while it is all that wasclaimed far it in the way of ever-bearing, it makes so few runners that it would be a great expense to get enough plants for even onetenth of an acre. And yet the Pan-American is the only American variety that could be depended upon for a crop out of season. A good deal has been written about the Louis Gauthier, St. Joseph and a few other French varieties, but if any one in the country has made money from the fruit we have not heard of it. From now on it will be different. Last spring $H$. Rockhill, of Conrad, Iowa, sent us for trial three varieties of ever-bearing strawberries. They were planted and cared for in the usual way. Most of the first blossoms were cut off and an abundance of runners were sent out. None were cut off. All three varieties continued in bearing until stopped by freezing weather in November. Not only the plants that were planted, but the young plants, fruited all summer. In many cases ripe berries were picked from ground runners not yet rooted. In addition to bearing all summer and fall in a very dry year, they made a matted row over three feet wide. Plants were green and healthy. Fruit was of medium size, roundish, bright red, firm, fragrant and delicious. They were neither watered, spaded nor mulched. Many of these berries have been sold by Mr. Rockhill, and the demand is greater than the supply.

No plants are for sale, neither are we interested in them. We expect to grow a large number for Mr. Rockhill this year. These will be put in the hands of a few reliable nurserymen in the spring of 1910 , so that each grower will grow his own plants to be offered in the spring of Igrr.

These berries will be in bearing here this year, from June till November, and all who are interested are invited to come and see them. 